\title{
Technology Validation of Optical Fiber Cables for Space Flight Environments
}

\author{
Melanie N. Ott, Sigma Research and Engineering/ NASA Goddard Space Flight Center \\ Patricia Friedberg, NASA Goddard Space Flight Center \\ Component Technologies and Radiation Effects Branch \\ Code 562, Greenbelt, Maryland 20771
}

\begin{abstract}
Periodically, commercially available (COTS) optical fiber cable assemblies are characterized for space flight usage under the NASA Electronic Parts and Packaging Program (NEPP). The purpose of this is to provide a family of optical fiber cable options to a variety of different harsh environments typical to space flight missions. The optical fiber cables under test are evaluated to bring out known failure mechanisms that are expected to occur during a typical mission. The tests used to characterize COTS cables include: vaccuum exposure, thermal cycling and radiation exposure. Presented here are the results of the testing conducted at NASA Goddard Space Flight Center on COTS optical fiber cables over this past year. Several optical fiber cables were characterized for their thermal stability both during and after thermal cycling. The results show how much preconditioning is necessary for a variety of available cables to remain thermally stable in a space flight environment. Several optical fibers of dimensions $100 / 140 / 172$ microns were characterized for their radiation effects at $-125^{\circ} \mathrm{C}$ using the dose rate requirements of International Space Station. One optical fiber cable in particular was tested for outgassing to verify whether an acrylate coated fiber could be used in a space flight optical cable configuration.
\end{abstract}

Keywords: fiber optic, radiation effects, thermal effects, communications, harsh environments, multimode, testing, cable, preconditioning.

\section{INTRODUCTION}

This is the fifth paper in a series of publications on the subject of characterization of commercial optical fiber and optical cables for space flight [1-4]. The objective of these publications is to provide information on the correct environmental usage of commercial cables for space flight through characterization testing to typical space flight environmental parameters. Several tests are used as a technology validation method to determine if an optical cable is suitable for a typical space flight environment. Included in this validation testing is outgass testing, thermal testing and radiation testing. Vibration testing is also used as a technology validation test but data from this type of testing is not included in this paper.

In most cases all materials used on space flight hardware are evaluated for outgassing characteristics in a vacuum environment to ASTM 595 (\% Total Mass Loss, \%TML must be less than 1\%).[5] If a material passes the ASTM 595E test than the material is considered acceptable for usage in a vacuum environment. A comprehensive database is available via a NASA GSFC website. [5]. In some cases when a material is known to outgass in a vacuum environment, the potential for usage still exists if the outgassing occurs in an area of the unmanned portion of a space craft such that these materials could not degrade the performance of any existing systems. Acrylate coatings used as protection on optical fiber are well known as "outgassers" and therefore are usually prohibited from space flight missions. However, acrylate coating used inside of a cable configuration was evaluated by Lockheed Martin to verify whether the acrylate coating added to the collected materials or mass loss. The testing showed that this configuration was acceptable by ASTM-595. The result of this testing was never verified at GSFC until now.

Thermal stability of optical cables is examined in two ways. The first is to examine the optical stability of fiber optic cable configuration given a changing thermal environment or during thermal cycling. The second is to examine the total amount of cable component shrinkage after exposure to a changing thermal environment or post thermal cycling. Both tests are used to determine if a cable is suitable for space flight. Presented here are results from testing using a generic thermal environment of $-55^{\circ} \mathrm{C}$ to $+125^{\circ} \mathrm{C}$.

Lastly of the subjects presented here, total ionizing dose radiation testing is used as a technology validation method of determining which fiber cable is suitable for space flight environment usage. The data presented is from testing using the 
International Space Station environment at two different dose rate exposures while at a temperature of $-121^{\circ} \mathrm{C}$. In most cases for cable configurations containing typical germanium doped 100/140 micron optical fiber, the effect of exposure at a low temperature represents the worst case for radiation induced attenuation. At colder temperatures optical fiber is less likely to anneal and recover from the color centers generated as a result of radiation exposure.

\section{THERMAL CHARACTERIZATION OF CABLES}

\subsection{DISCUSSION OF EXPERIMENTS ON THERMAL CHARACTERIZATION}

For this thermal characterization, five fiber optic cable configurations were tested: one from W.L.Gore, two from Brand Rex, and two from RIFOCS (manufacturer Northern Lights). All cables chosen for this testing, were chosen based on the intention of these cables to be used for space flight applications. These cables were designed to be commercially available (all but the OC1614 which was made for space station) but also space flight ruggedized cable configurations. One of the Brand Rex cables included in this study the OC1008 is actually a discontinued item but was included for comparison purposes since this cable was used for both the TRMM and XTE missions. The W.L. Gore cable was designed to be used in the $-55^{\circ} \mathrm{C}$ to $+125^{\circ} \mathrm{C}$ thermal environment and the Brand Rex space station cable $0 \mathrm{C} 1614$ was designed for the $-100^{\circ} \mathrm{C}$ to $+75^{\circ} \mathrm{C}$, but most of the other candidates have a smaller thermal range for performance. It is important to note that the OC1614 is based on the configuration described below which includes a polyimide coated fiber and it is very likely that the cable could be operated all the way to $+200^{\circ} \mathrm{C}$. Brand Rex does confirm that although the OC1614 was made to the SSQ21654 specification it could be capable of temperatures well beyond the upper limit of $+75^{\circ} \mathrm{C}$. Table 1 describes the configurations of the cables tested with some details about their dimensions and specified thermal ratings. The cables listed in Table 1 with the exception of the OC1008 are in fact available or will be available if not already, with other types of optical fiber. Brand Rex, W.L.Gore and RIFOCS have communicated the intention of using these configurations to manufacture for various different applications that require other fiber diameters that are the standard outer diameter of 125 microns or the 140 micron non standard fiber with acrylate and polyimide coatings. Therefore, the products listed here are only an example of the family of cables that are available using these configurations and these cables were chosen based on availability at the time of this testing.

\begin{tabular}{|c|c|c|c|c|c|c|}
\hline $\begin{array}{l}\text { Vendor } \\
\text { Cable Part \# }\end{array}$ & $\begin{array}{l}\text { Cable } \\
\text { Configuration }\end{array}$ & Fiber Type & $\begin{array}{l}\text { Secondary } \\
\text { Buffer }\end{array}$ & $\begin{array}{l}\text { Strength Members/ } \\
\text { Jacket }\end{array}$ & $\begin{array}{l}\text { Outer } \\
\text { diameter }\end{array}$ & Thermal rating \\
\hline $\begin{array}{l}\text { W.L. Gore } \\
\text { FON1004 }\end{array}$ & $\begin{array}{l}\text { Tight Tube with } \\
\text { Metal braid over } \\
\text { GoreTex buffer }\end{array}$ & $\begin{array}{l}\text { Single mode, } \\
1310 / 1550 \mathrm{~nm} \\
\text { acrylate buffer }\end{array}$ & $\begin{array}{l}\text { Gore Tex } \\
\text { Expanded } \\
\text { PFA }\end{array}$ & Kevlar/FEP & $2.5 \mathrm{~mm}$ & $-55^{\circ} \mathrm{C}$ to $+125^{\circ} \mathrm{C}$ \\
\hline $\begin{array}{l}\text { Brand Rex } \\
\text { OC1614 } \\
\text { (SSQ-21654 } \\
\text { Rev. B) } \\
\end{array}$ & Tight tube & $\begin{array}{l}\text { Multimode } \\
100 / 140 / 170 \\
\text { hermetic seal/ } \\
\text { polyimide buffer }\end{array}$ & $\begin{array}{l}\text { FEP } \\
\text { Teflon }\end{array}$ & $\begin{array}{l}\text { Teflon impregnated } \\
\text { fiber glass/FEP }\end{array}$ & $2.1 \mathrm{~mm}$ & $-100^{\circ} \mathrm{C}$ to $+75^{\circ} \mathrm{C}$ \\
\hline $\begin{array}{l}\text { Brand Rex } \\
\text { OC1008 }\end{array}$ & Loose tube & $\begin{array}{l}\text { Multimode } \\
100 / 140 / 500 \text { acrylate buffer } \\
\text { from corning now discontinued }\end{array}$ & Hytrel & $\begin{array}{l}\text { Teflon impregnated } \\
\text { fiber glass/ETFE }\end{array}$ & $2.77 \mathrm{~mm}$ & $-55^{\circ} \mathrm{C}$ to $+85^{\circ} \mathrm{C}$ \\
\hline $\begin{array}{l}\text { RIFOCS } \\
\text { H06 }\end{array}$ & Tight tube & $\begin{array}{l}\text { Multimode } \\
62.5 / 125 / 250\end{array}$ & Hytrel & Kevlar/Tefzel & $2.4 \mathrm{~mm}$ & $-40^{\circ} \mathrm{C}$ to $+95^{\circ} \mathrm{C}$ \\
\hline $\begin{array}{l}\text { RIFOCS } \\
\text { HLI }\end{array}$ & Tight tube & $\begin{array}{l}\text { Single mode, } \\
1310 / 1550 \mathrm{~nm} \\
\text { acrylate buffer }\end{array}$ & Hytrel & Kevlar/Tefzel & $2.4 \mathrm{~mm}$ & $-40^{\circ} \mathrm{C}$ to $+95^{\circ} \mathrm{C}$ \\
\hline
\end{tabular}

Most of the tested cables are not rated for the extremes of $-55^{\circ} \mathrm{C}$ to $+125^{\circ} \mathrm{C}$, and it is usually due to the rating of the acrylate coating on the fiber itself which is $+85 \mathrm{C}$. However, this test was conducted to determine the amount of thermally induced shrinkage of the cable components and the optical performance as a result so the limits were extended to the $-55^{\circ} \mathrm{C}$ to $+125^{\circ} \mathrm{C}$ range for all cables tested. Because of this, it is important to note that all the optical cable candidates with the exception of the W.L. Gore FON 1004 were taken beyond their thermal specifications. The ramp rates for all of the thermal testing was $2^{\circ} \mathrm{C} /$ min with dwells of 28 minutes per temperature extreme.

For monitoring the cables actively, each cable was placed inside the chamber with terminated ST connectors just outside the feed-through hole to the oven. There were reference cables connected to the sources and detectors with the cable under test in between the two sets. Insertion loss of the cable assembly was not the issue of concern here. Instead it was the change in transmitted optical power during the thermal cycling. 
The sources used for transmission of optical power through the cables were the RIFOCS 252A and the RIFOCS 752L both used at $1300 \mathrm{~nm}$. The detector used to convert the optical signal to an electrical signal was the HP8153A with HP81532A power sensor modules. For the insitu testing, a Labview program was written to acquire data and store it in a text file. One cable of each type was tested for optical transmittance changes before, during and after thermal cycling to a total of 48 cycles.

\subsection{RESULTS OF THERMAL CHARACTERIZATION}

The thermal testing was conducted in two parts. During part one of the testing all cables were cycled and measured post each 8 cycle session for dimensional shrinkage in the longitudinal direction only and some optical measurements were made. Part two of this testing was focused on the optical performance of these cables (with most of them being taken well outside of their thermal specifications) during thermal cycling. The overall optical fluctuations that occur during the cycling are used as a characterization of the thermal expansions and contractions due to the CTE of materials used in the configuration. The data for part one of this thermal characterization is presented in Figure 1.

\% Shrinkage of cable jacketing vs. thermal cycle, sample set 1

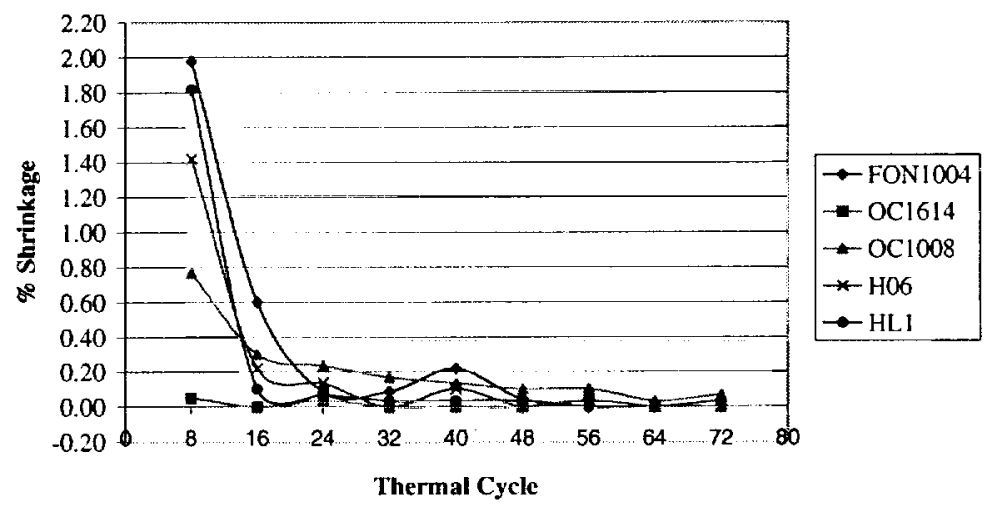

Figure 1: Cable configuration shrinkage in length for five different cables up to a total of 72 thermal cycles.

There was no visible damage that occurred as a result of taking most of the cables outside of there respective thermal specifications. It is interesting to note that the FON1004 and both RIFOCS cables had jacket shrinkage but the kevlar and other buffer materials did not shrink back. In the thermal tests conducted and reported in reference 2, this was not the case. All cable components would shrink back exposing only the coated optical fiber.

\subsection{SUMMARY OF THERMAL CHARACTERIZATION EXPERIMENT}

Table 2 summarizes the results of the thermal characterization study. The total \% shrinkage in cable component length after 72 thermal cycles is in column two where both data sets are included; the second data set is in parenthesis. In the third column, the total \% shrinkage after 24 cycles is presented. The purpose for showing the results after 24 cycles, is that in many cases 20 to 24 cycles is used to "precondition" optical cables such that they will cease to shrink in length during further thermal cycling. Column four lists the numbers of thermal cycles that it took for the cables to shrinkage less than .1\% as compared to the cable length after the previous 8 cycle session. The optical transmission changes that occurred as a result of thermal cycling and were monitored during thermal cycling at $1300 \mathrm{~nm}$, are listed in column five. The comments on those transmission changes are listed in the last column of table 2 . Since only one 3 meter length was tested of each type of cable there is only one set of data presented as a result of insitu monitoring of the optical transmission during thermal cycling. The data for the optical transmission changes were normalized to match a 3 meter length exactly since each cable was approximately but not exactly 3 meters in length. 
Table 2: Summary of results from thermal testing both length shrinkage and insitu optical transmission monitoring.

\begin{tabular}{|c|c|c|c|c|c|}
\hline Cable & $\begin{array}{l}\text { Total \% } \\
\text { Shrinkage }\end{array}$ & $\begin{array}{c}\text { Total \% } \\
\text { Shrinkage } \\
\text { after } 24 \text { cycles. }\end{array}$ & $\begin{array}{l}\text { Cycles to } \\
<0.1 \%\end{array}$ & $\begin{array}{c}\text { Insitu } \\
\text { transmission } \\
\text { changes, } 3 \mathrm{~m} \\
\end{array}$ & $\begin{array}{l}\text { Comments } \\
\text { on transmission }\end{array}$ \\
\hline $\begin{array}{l}\text { W.L. Gore } \\
\text { FoN1004 }\end{array}$ & $2.94(2.99)$ & $0.75(0.24)$ & $56(40)$ & $<.05 \mathrm{~dB}$ & $\begin{array}{l}\text { After } 2 \text { cycles, steady below } \\
.05 \mathrm{~dB}\end{array}$ \\
\hline $\begin{array}{l}\text { Brand Rex } \\
\text { oc1614 }\end{array}$ & $0.12(0.13)$ & $0.03(0.0)$ & $<8(<8)$ & $<.10 \mathrm{~dB}$ & $\begin{array}{l}\text { Increased from less }<.025 \mathrm{~dB} \\
\text { upto } .10 \mathrm{~dB} \text { as test progresses }\end{array}$ \\
\hline $\begin{array}{l}\text { Brand Rex } \\
\text { OC1008 }\end{array}$ & $1.90(1.80)$ & $0.44(0.44)$ & $56 *(56)$ & $<.50 \mathrm{~dB}$ & $\begin{array}{l}\text { Increases from } .05 \text { dB to } .45 \\
\text { dB as test progresses }\end{array}$ \\
\hline $\begin{array}{l}\text { RIFOCS } \\
\text { H06 }\end{array}$ & $1.90(1.87)$ & $0.14(0.17)$ & $24(24)$ & $<.10 \mathrm{~dB}$ & $\begin{array}{l}\text { After } 2 \text { cycles steady below } \\
.10 \mathrm{~dB}\end{array}$ \\
\hline $\begin{array}{l}\text { RIFOCS } \\
\text { HLI }\end{array}$ & $2.12(2.13)$ & $0.10(0.17)$ & $16 *(16)$ & $<.40 \mathrm{~dB}$ & $\begin{array}{l}\text { A fter } 13 \text { cycles drops to below } \\
.05 \text { steady for the rest of test }\end{array}$ \\
\hline
\end{tabular}

The optical power transmission transients were calculated by comparing adjacent optical power peaks and losses within a thermally induced cycle. In this way the LED output power drift was eliminated. The total optical power transmission change, which is presented in these figures, is calculated by comparing the optical power maximum to the optical power minimum in a given cycle. Although the intention was to collect data for 48 thermal cycles total, in some cases not all data was captured due to operation error.
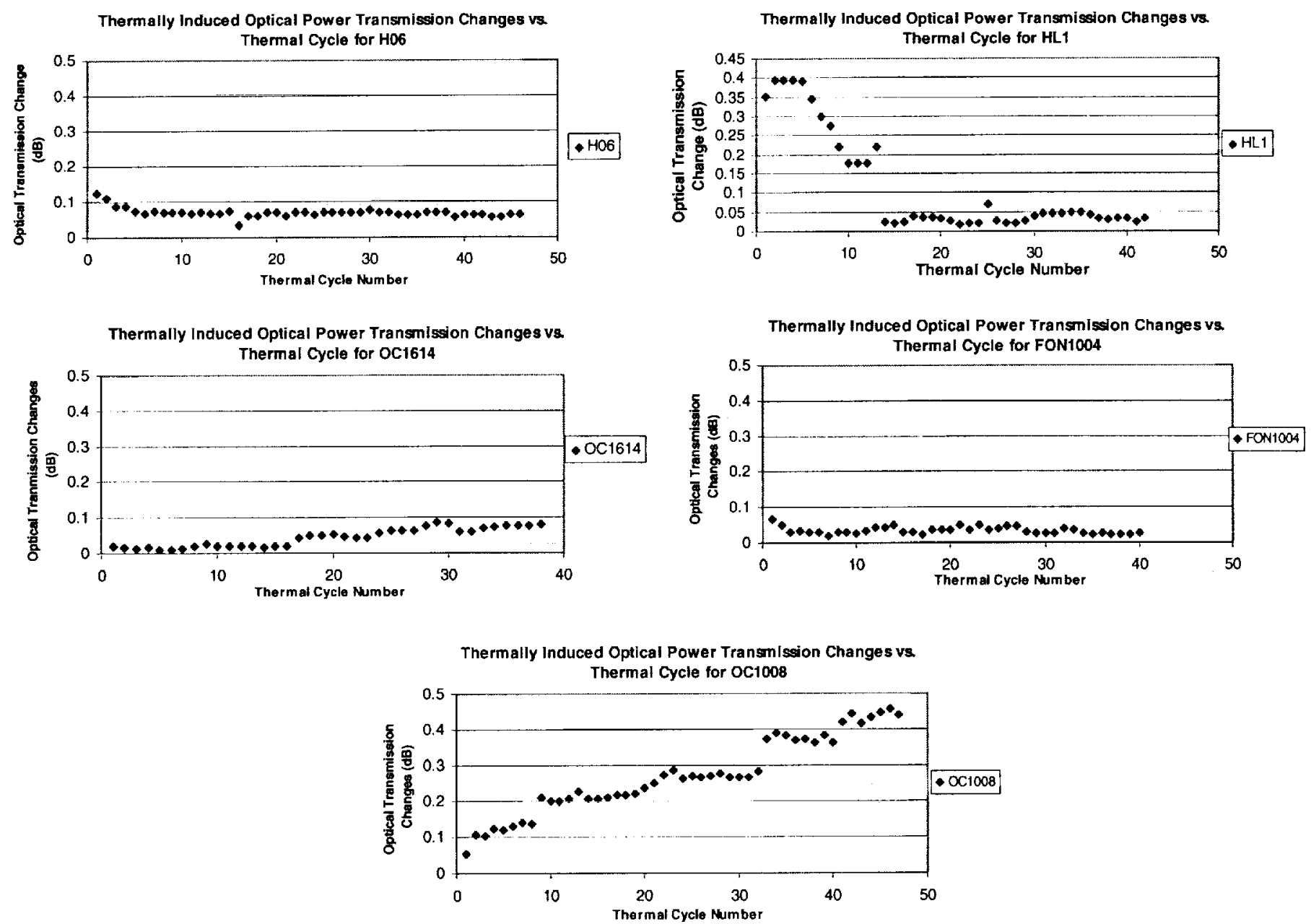

Figure 2: Optical transmission changes monitored during thermal cycling a) H06, b) HL1, c) OC1614, d) FON1004 and e) $O C 1008$.

The optical transmission changes for the H06 were less than $0.1 \mathrm{~dB}$ (Figure 2a) for the duration of the testing on a length of cable approximately 3 meters long. The optical transmission changes for HLl (Figure 2b) decrease considerably after 13 thermal cycles down to less than $.05 \mathrm{~dB}$. The FON1004, (Figure 2c) for the duration of the testing had fluctuations less than $.05 \mathrm{~dB}$. The $\mathrm{OC} 1614$ (Figure 2d) and the OC1008 (Figure 2e) both had increased power fluctuations during thermal cycling 
as the cycling progressed. This was most likely due to the fact that both cables have a loose tube construction. It would make sense that shrinking cable would force the fiber into a tighter helix and make the fiber more sensitive to the expansion and contraction caused by the materials CTE. The OC1614 shrinks very little and even though there is a slight increase in the thermally induced transmission transients, the total swing never reach more than $0.1 \mathrm{~dB} / 3 \mathrm{~m}$.

During this testing it was expected that the single mode cables would perform better than the multimode cables in terms of stability due to the short lengths used and that indeed was the case. Launch conditions were not regulated such that the multimode fiber would reach its equilibrium point for power distribution across the traveling modes. In typical space flight applications launch conditions are not always controlled or at optimal levels and therefore they were not regulated here.

It was expected that during insitu testing that when the temperature was at a maximum, the optical power transmission of the cable under test would be at a maximum as well and that during a low thermal extreme that the power would reach its minimum value. In most cases this was true except for the OC1614. Just the opposite appeared to occur. Two more addition tests were conducted on cables from another source to confirm that indeed for the cable OC1614, the optical maximum would be reached during the soak at $-55^{\circ} \mathrm{C}$ and that during the $+125^{\circ} \mathrm{C}$ soak, the optical transmission would reach a minimum.

\subsection{CONCLUSIONS ON THERMAL CHARACTERIZATION}

The overall rankings of how the cable candidates performed are in table 3. The ranking is somewhat subjective for the optical tests in that multimode cables are being compared to single mode cables. It is expected that the highest ranking cables for optical performance should be the FON1004 and the HLl. For the most part these do appear to be more optically stable than the multimode cables. Comparing the HL1 and the FON1004 to each other the FON1004 slightly outperforms the HLI for the optical testing. The difference here could be that the $\mathrm{HLl}$ was being cycled at a temperature $+30^{\circ} \mathrm{C}$ above and $-15^{\circ} \mathrm{C}$ below the temperatures for which it is rated. The HL1 did have large thermally induced transmission transients during the first 13 cycles but decreased after the 13 th cycle and remained at a level less than $.05 \mathrm{~dB}$. This again may be due to fact that the cable is being taken well above its rated thermal limit. In addition it is also interesting to note where the majority of the linear cable component shrinkage becomes less than .1\%, and that it is after the 16 th thermal cycle. It may be that the reduction in shrinkage actually occurred after the 13th cycle but that during this testing the thermal effects were only measured after 8 cycle sessions. The data here indicates the H06 is a good performer once the 13th cycles have been completed. This gives an indication of how much "preconditioning" the HLl requires to reach a thermal stability, given these thermal cycle extremes of $-55^{\circ} \mathrm{C}$ to $+125^{\circ} \mathrm{C}$. There is a RIFOCS preconditioning procedure that once performed, should allow the cable to remain thermally stable. Verification of the preconditioning procedure was conducted in addition to this testing. The shrinkage was measured after the procedure was used and then again after every 4 thermal cycles using the range $-40^{\circ} \mathrm{C}$ to $+95^{\circ} \mathrm{C}$ for which the cable is rate by specification. The test results showed that although the majority of the shrinkage occurred from the preconditioning process as expected, the shrinkage did not decrease to less than . $1 \%$ until an additional 16 cycles. The thermal cycling was performed using the temperature extremes $-40^{\circ} \mathrm{C}$ to $+95^{\circ} \mathrm{C}$ with a 30 minute dwell and a ramp rate of $2^{\circ} \mathrm{C} / \mathrm{min}$. These extremes were based on the thermal rating of the HL1 cable.

The FON1004 cable ranks the lowest in the total amount of thermally induced shrinkage although the shrinkage did stabilize somewhere after 48-56 cycles. Optically, this cable performed very well even with the large amount of cable component shrinkage. Again, we see that preconditioning for this cable is absolutely necessary for up to 50 cycles to reach less than $0.1 \%$ shrinkage.

Table 3: Ranking summary of cables in terms of best performance, $I$ being the best and 5 being the worst of the total.

\begin{tabular}{|l|l|l|l|}
\hline Test & $\begin{array}{l}\text { Total Length } \\
\text { Shrinkage }\end{array}$ & $\begin{array}{l}\text { Cycles to less } \\
\text { than .1\% } \\
\text { Shrinkage }\end{array}$ & $\begin{array}{l}\text { Insitu } \\
\text { transmission } \\
\text { stability }\end{array}$ \\
\hline Rank 1 & OC1614 & OCl614 & FON 1004 \\
\hline Rank 2 & H06 & HL1 & OC1614 \\
\hline Rank 3 & OC1008 & H06 & H06 \\
\hline Rank 4 & HLl & FON1004 & HLl \\
\hline Rank 5 & FON1004 & OC1008 & OC1008 \\
\hline
\end{tabular}

Of the multimode cables the OC1614 is by far the best performer for all testing conducted when compared to the multimode cables. The H06 appears to be second when compared to the OC1614. However, where a preconditioning procedure may not be necessary for the $\mathrm{OC} 1614$ it is absolutely necessary for the H06 where the bulk of the linear shrinkage occurs in the 
first 32-40 thermal cycles. It may or may not be the case that the configuration materials in the HLI and the H06 are identical. If the assumption is that they are in fact the same, then the variability from lot to lot with respect to the lengthwise component shrinkage could be a factor of 2 . This could explain why for the HLl the bulk of the length shrinkage occurred around 13-16 cycles and for the H06 the bulk of the shrinkage occurred after 32-40 cycles. Without a large enough number of cable samples from different lots this can not be verified.

For most of the testing conducted, the available cables perform better than the vintage OC1008 optical fiber cable currently used in space flight. Since the thermal induced transients becoming larger as the loose tube configuration cables, OC1008 and OC1614 are cycled, preconditioning to eliminate the bulk of the shrinkage must be conducted prior to termination of the optical connectors. In fact, in all cases preconditioning should be performed prior to termination to avoid reliability hazards from the fiber being pulled out of the ferrule from the stress or leaving exposed fiber between the cable components and the connector itself.

The OC1614 was the superior performer throughout the testing and was taken well beyond its specification level. Just as this testing was completed, the International Space Station Mission reported failures on their space flight cable, which is the OC1614. The root cause report is now available.[6]

\section{RADIATION CHARACTERIZATION OF OPTICAL FIBER}

\subsection{BACKGROUND}

The testing of Lucent SFT optical fiber was conducted to characterize several types of the Lucent SFT 100/140/172 carbon coated product for use in a harsh space flight environment. The environmental parameters used in this testing were extracted from the new International Space Station (ISS) specification 21657 Revision N/C.[7] The environmental parameters include a constant temperature of $-121^{\circ} \mathrm{C}$ for a maximum of six days during which the fiber is exposed to total ionizing radiation exposure as a result of solar flare events, passes through the South Atlantic Anomaly, and background radiation. The ISS specification requirement includes testing of cable to three different levels of the expected total ionizing dose (TID) in a cold environment. The objective of this testing was to simulate the worst of the actual conditions during a six day cold temperature exposure without over testing. In order to accomplish this, two dose rates were to be used for estimating the radiation induced attenuation performance of the cable, $42 \mathrm{rads} / \mathrm{min}$ for two hours to simulate the solar flare activity and .5 $\mathrm{rads} / \mathrm{min}$ to simulate passes through the South Atlantic Anomaly, SAA and background radiation. The specification requires a TID radiation exposure on the optical fiber cable for a total of six days at a constant temperature of $-121{ }^{\circ} \mathrm{C}+1-4^{\circ} \mathrm{C}$. This test was then to continue at the second dose rate of exposure, but at room temperature for an additional 48 hours or once a saturation level had been reached for radiation induced attenuation.

\subsection{DISCUSSION OF EXPERIMENT ON RADIATION CHARACTERIZATION}

In order to use the TID cobalt 60 chamber at NASA Goddard Space Flight Center with a thermal chamber and necessary shielding, the highest dose rate attainable for exposurc on an optical fiber reel was $28.3 \mathrm{rads} / \mathrm{min}$. Therefore, two tests had to be conducted at different dose rates. It was expected that the highest radiation induced attenuation would occur after an exposure to $5.1 \mathrm{krads}$ at $42 \mathrm{rads} / \mathrm{min}$. That being the case, it was considered adequate to use two different dose rates for testing and extrapolate to obtain the actual required radiation induced attenuation values.

The optical fibers under test (DUTs) are described in Table 1. Optical fiber F3 is the "rad hard" fiber most space flight projects have used when a 100/140/172 micron hermetic fiber was required. F2 is the same fiber as F3, but manufactured a different way using a synthetic silica deposition tube. Both F2 and F3 are doped with germanium and boron. F1 is a commercially available non "rad hard" optical fiber that is doped with germanium and phosphorous. Fl was included in this study to determine if in fact, a non radiation hardened optical fiber could be used in a harsh space flight environment such as the ISS specification illustrates.

\begin{tabular}{|c|c|c|c|c|}
\hline $\begin{array}{l}\text { Fiber ID } \\
\text { for Test }\end{array}$ & Part Number & $\begin{array}{l}\text { Lot } \#, \text { Test } 1 \\
(96 \text { meters })\end{array}$ & $\begin{array}{l}\text { Lot \#, Test } 2 \\
(100 \text { meters })\end{array}$ & Description \\
\hline F3 & $\mathrm{BF} 05202$ & $\mathrm{CD} 0712 \mathrm{XA}$ & $\mathrm{CD} 0712 \mathrm{XB}$ & $\begin{array}{l}\text { SL BASE Prem, Flightguide } 100 / 140 / 172 \text { micron, } \\
\text { Ge-B-doped, natural silica deposition tube, carbon coated }\end{array}$ \\
\hline F2 & $\mathrm{BF} 05202$ & $\mathrm{CD} 0892 \times \mathrm{C}$ & CD0892XC & $\begin{array}{l}\text { New Flight guide, Ge- B- doped, synthetic silica deposition tube, carbon } \\
\text { coated }\end{array}$ \\
\hline Fl & CF04530-04 & CD0266XA & CD0266XA & standard fiber, carbon coaled Ge-P- doped, synthetic silica deposition tube) \\
\hline
\end{tabular}


The Cobalt 60 chamber housed the nitrogen tanks and thermal chamber set to operate at $-121^{\circ} \mathrm{C}$, with the spool holding approximately $100 \mathrm{~m}$ of each type of fiber F1, F2, and F3 inside the thermal chamber. The fiber spool was shielded by a 62.5 milli-inches lead box and a 62.5 milli-inches aluminum plate to limit secondary $\mathrm{X}$-rays and reflections that could lead to other types of radiation damage not included in this study. The terminated FC connector ends of each fiber DUTs (devices under test) were fed through the thermal chamber feed-through hole. The fiber DUTs were mated to 25 meter lead out cables that were fed through the chamber feed through conduit and led to the source and detector setups outside of the chamber.

A light emitting diode (LED) source was connected to a reference cable, which was mated to a mandrel wrap and then to an attenuator. In the first test the $1300 \mathrm{~nm}$ LED source was the EXFO FLS-2100 which included an attenuator and in this case the mandrel wrap was connected between the output of the source and the input coupler. For Test 2, the RIFOCS 752L dual wavelength source was used with the JDS FITEL HA9 optical variable attenuator and in this case the mandrel wrap was connected between the source and the attenuator. The purpose of the attenuator was to reduce the power to the DUTs such that the input optical power was equal to or less than 1 microwatt at $1300 \mathrm{~nm}$. The input coupler was connected to the output of the attenuator for Test 2 . The input coupler was connected to the input "lead-in" cables that were fed through the radiation chamber feed through wall conduit. The input lead-in cables were then connected to the fiber DUTs and mounted to the top of the thermal chamber. The fiber spooled onto the reel, was very closely spooled on one side of the reel and filled a space of less than 1 inch along the reel width. This was to insure that each fiber was getting the same radiation exposure. All fiber on the spool was unjacketed and spooled such that the leads in and out were not considered part of the $100 \mathrm{~m}$.

The chamber lead-out cables were connected to HP8153A power meters with HP81532A power sensor modules. The system was operated at $1300 \mathrm{~nm}$. Labview software via a Dell laptop computer controlled the data acquisition from the HP detectors. Data was logged once per minute, time stamped and stored in a text file with the first data point recorded prior to radiation exposure. All lead and reference cables contained 100/140 micron optical fiber.

Two tests were conducted for the purpose of data extrapolation to $42 \mathrm{rads} / \mathrm{min}$ for two hours and $.5 \mathrm{rads} / \mathrm{min}$ for a total of six days (including the two hours) at a constant temperature of $-121^{\circ} \mathrm{C}$. The thermal chamber was positioned in front of the radiation source shutter to achieve the maximum radiation dose rate at the location of the fiber spool. The largest dose rate achieved was $28.3 \mathrm{rads} / \mathrm{min}$. Therefore, the second dose rate was scaled proportionally from the actual lower dose rate to .34 $\mathrm{rads} / \mathrm{min}$. The first test involved exposing the fiber, while at $-121^{\circ} \mathrm{C}$, to $28.3 \mathrm{rads} / \mathrm{min}$ for three hours, which was approximately a total dose of $5.1 \mathrm{Krads}$. Following the high dose rate exposure, a low dose rate exposure of .34 rads/min was used for the rest of the six-day duration. The dose rate for Test 2 was scaled by a factor of two and therefore a dose rate of $14.2 \mathrm{rads} / \mathrm{min}$ was used for the initial $5.1 \mathrm{Krads}$ (six hours). This was followed by a six-day exposure of .17 rads/min at $121^{\circ} \mathrm{C}$ after which the exposure continued at room temperature, $25^{\circ} \mathrm{C}$ for two additional days.

The attenuators on both test set-ups were used to limit the input power to the DUTs to either 1 microwatt or less. This was done as a precaution to avoid most of the photobleaching effects of the source on the radiation performance of the optical fiber. Typically, the higher the optical power is, the more aid is lent to fiber in annealing due to this effect known as photobleaching, although germanium doped DUTs show little dependence on the amount of optical power injected.[8] Regardless, the optical power was limited to between .5 and 1 microwatt. Throughout testing the temperature of the thermal chamber was monitored and logged into a text file. The measured temperature throughout each experiment was $-125^{\circ} \mathrm{C}$.

\subsection{RESULTS OF RADIATION CHARACTERIZATION}

The radiation exposure test conditions for total dose and dose rates of each test are represented in table 5 .

Table 5 Radiation Test Conditions

\begin{tabular}{|l|l|l|}
\hline Test & High dose rate condition $(5.1 \mathrm{Krads})$ & Low dose rate condition $(-6.3 \mathrm{Krads})$ \\
\hline 1 & $28.3 \mathrm{rads} / \mathrm{min}, 3$ hours & $.34 \mathrm{rads} / \mathrm{min}, 141$ hours \\
\hline 2 & $14.2 \mathrm{rads} / \mathrm{min}, 6$ hours & $.17 \mathrm{rads} / \mathrm{min}, 138$ hours \\
\hline
\end{tabular}

The data was separated into high dose rate and low dose rate sections for ease of analysis. The actual data for the high and low dose rate sections of test 1 and 2 for each fiber are in Figures 3,4 and 5. For Figures 3 through 5, the graphs in a) are the high dose rate segments of the radiation induced attenuation data, for F1, F2 and F3 respectively. The plots in b) of Figures 3 through 5 are the low dose rate segments of the radiation induced attenuation data collected for F1, F2 and F3 respectively. The data from test 1 was normalized to $100 \mathrm{~m}$ such that the lengths would be consistent with test 2 . 

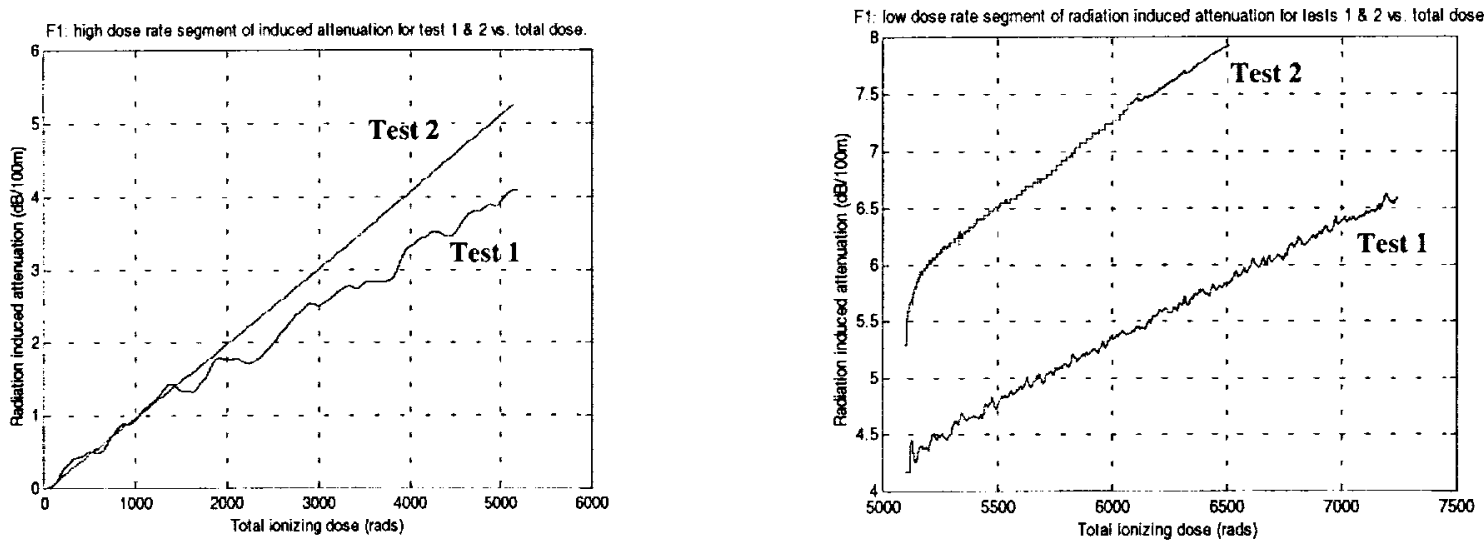

Figure 3: Optical fiber F1, A) High dose rate segment of radiation induced attenuation for Test 1 and 2 at $-125^{\circ} \mathrm{C}$ with a total dose of $5.1 \mathrm{Krads}$. B) Low dose rate segment of radiation induced attenuation for Test 1 and 2 at $-125^{\circ} \mathrm{C}$ to a total dose of $6.5 \mathrm{Krads}$ for Test 2 and $7.25 \mathrm{Krads}$ for Test 1 .
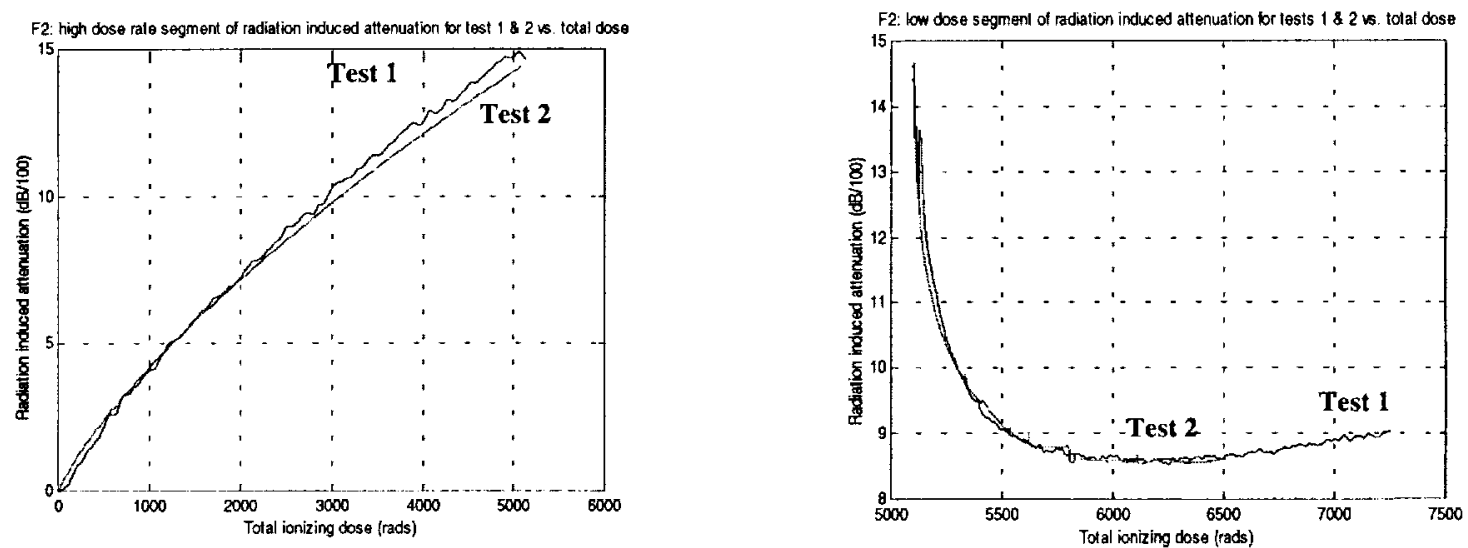

Figure 4: Optical fiber F2, A) High dose rate segment of radiation induced attenuation forTests 1 and 2 at $-125^{\circ} \mathrm{C}$ with a total dose of $5.1 \mathrm{Krads}$, B) low dose rate segment of radiation induced attenuation for Tests $1 \& 2$ at $-125^{\circ} \mathrm{C}$ to a total dose of $6.5 \mathrm{Krads}$ for Test 2 and $7.25 \mathrm{Krads}$ for Test 1 .
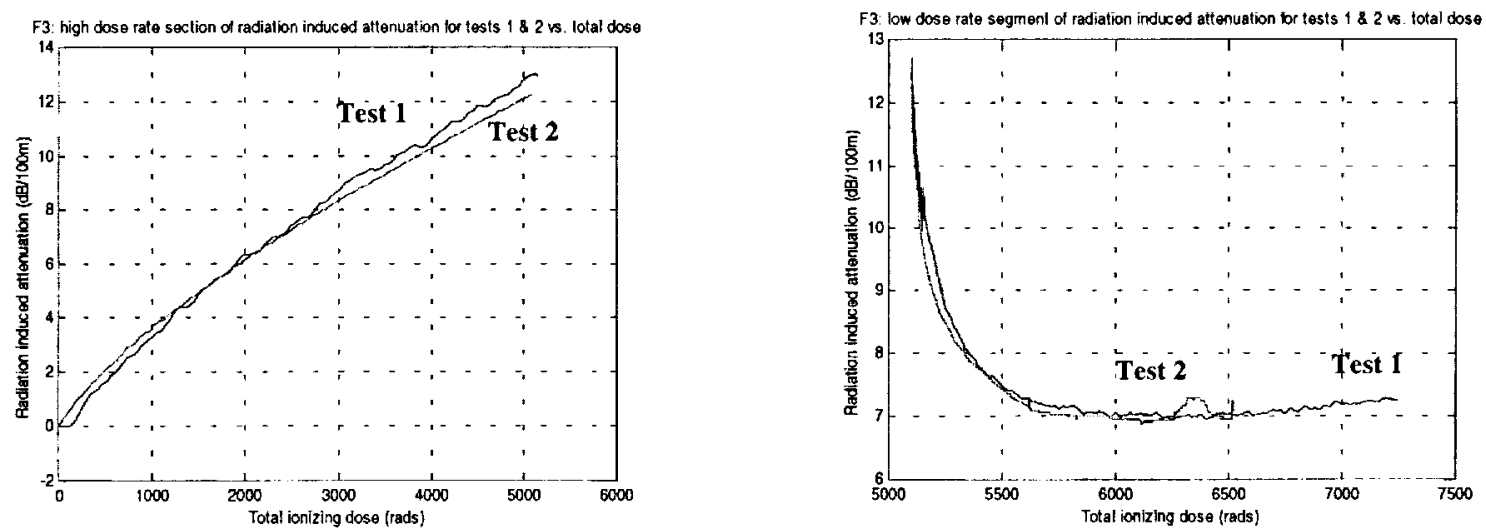

Figure 5: Optical fiber F3 A) high dose rate segment of the radiation induced attenuation data for Test 1 at $28.3 \mathrm{rads} / \mathrm{min}$ and Test 2 at 14.2 rads/min; B) low dose rate segment of the radiation induced attenuation data for Test $1.34 \mathrm{rads} / \mathrm{min}$ and Test 2 at .17 rads/min to lotal dose of 5.1 Krads at $-125^{\circ} \mathrm{C}$

The data for F2 and F3 illustrated behavior typical for germanium doped fiber. In contrast, the data for F1 showed data atypical of germanium doped fiber. It is surmised that Fl's behavioral deviation was due to the phosphorous doping of the optical fiber (phosphorous is typically used to raise index of refraction while boron is used to lower the index of a silica fiber). For F2 and F3, once the dose rate was lowered to $.34 \mathrm{rads} / \mathrm{min}$ and to $.17 \mathrm{rads} / \mathrm{min}$ during test 1 and 2 respectively, the radiation induced attenuation levels off and saturates. Figures $4 b$ and $5 b$ show this behavior as expected from germanium 
doped optical fiber. This behavior indicates that even at an elevated dose rate of $.5 \mathrm{rads} / \mathrm{min}$ both optical fibers will saturate at the same attenuation in which they saturated for both $.34 \mathrm{rads} / \mathrm{min}$, and $.17 \mathrm{rads} / \mathrm{min}$. This simplifies the extrapolation necessary to allow us to focus on only the high dose rate segments of the tests for F2 and F3 to answer how these fibers would act in the ISS space radiation environment. This is not the result for F1 however, it does continue to attenuate even after the dose rate is lowered, just about linearly.
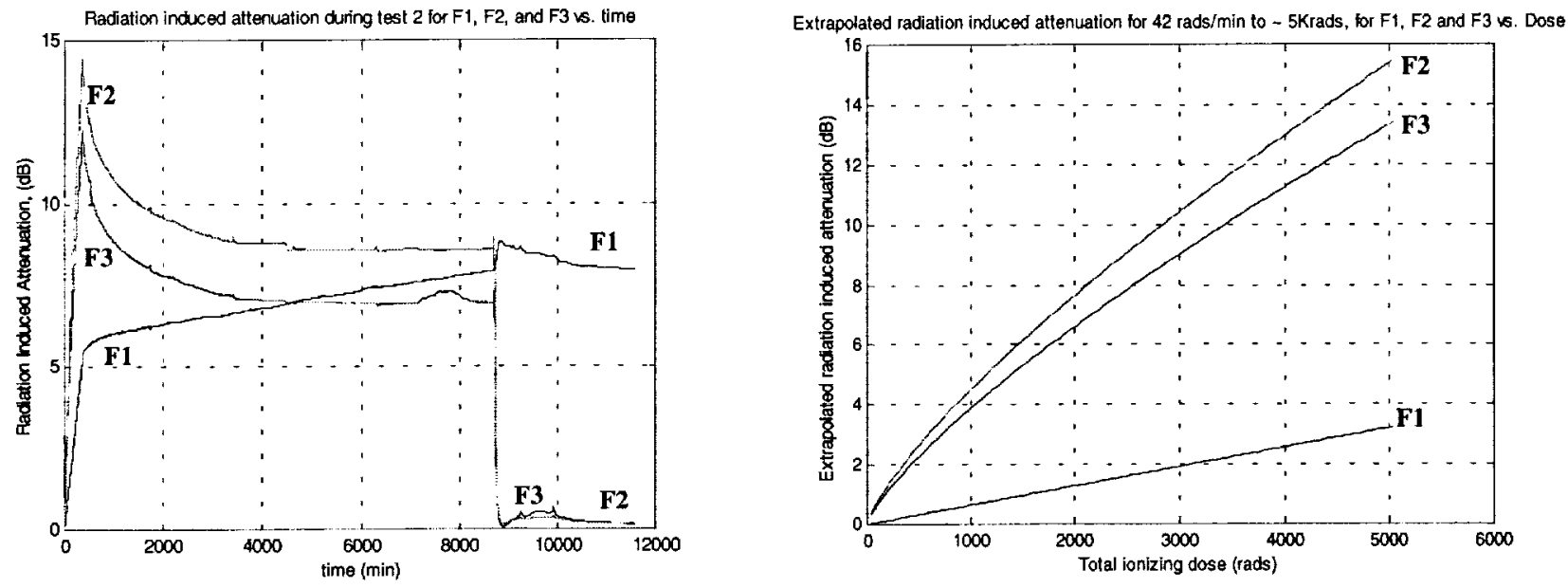

Figure 6 a) complete data set for radiation induced attenuation graphs of all fibers during test 2 vs. time, b) extrapolation of radiation induced attenuation data to 42 rads/min for all fibers tested.

The entire data set for fibers F1, F2 and F3 are graphed in Figure 6a for test 2. This plot illustrates how the optical fibers behave in comparison to one another once the temperature is elevated to $+25^{\circ} \mathrm{C}$ after being at a constant $-125^{\circ} \mathrm{C}$ for six days. Again F2 and F3 behave identical while F1 continues to increase. The radiation exposure for test 2 continued at $.17 \mathrm{rads} / \mathrm{min}$ after the temperature was elevated to $+25^{\circ} \mathrm{C}$. The plots for each fiber in Figure $6 \mathrm{a}$ are marked by name at the beginning and end of the corresponding data.

The high dose rate data from each test was used to extrapolate to the ISS dose rate of $42 \mathrm{rads} / \mathrm{min}$ and the results of this extrapolation are in Figure $6 \mathrm{~b}$. The model $A=C D^{f}$ is used to describe the high dose rate behavior of all three fibers, where $C$ is a constant related to dose rate, $\mathrm{D}$ is the total ionizing dose and $\mathrm{f}$ is less than one.[9] The equations that govern the behavior of F1, F2 and F3 at $42 \mathrm{rads} / \mathrm{min}$ up to a total dose of $5.04 \mathrm{Krads}$ while at $-125^{\circ} \mathrm{C}$ are in Table 6 along with the values of attenuation for the different dose rates.

Table 6: Summary of radiation induced attenuation and extrapolated attenuation for all optical fibers.

\begin{tabular}{|c|c|c|c|}
\hline Dose \& Temperature Condition & $\begin{array}{l}\text { Radiation Induced } \\
\text { Attenuation } \\
\text { F1 }\end{array}$ & $\begin{array}{l}\text { Radiation Induced } \\
\text { Attenuation } \\
\text { F2 }\end{array}$ & $\begin{array}{c}\text { Radiation Induced } \\
\text { Attenuation } \\
\text { F3 }\end{array}$ \\
\hline $28.3 \mathrm{rads} / \mathrm{min} 5.1 \mathrm{Krads},-125^{\circ} \mathrm{C}$ & $\begin{array}{c}4.1 \mathrm{~dB} / 100 \mathrm{~m} \\
\mathrm{~A}=8.1^{*} 10^{-4} \mathrm{D}^{.999}\end{array}$ & $\begin{array}{l}14.9 \mathrm{~dB} / 100 \mathrm{~m} \\
\mathrm{~A}=23^{*} 10^{-3} \mathrm{D}^{76}\end{array}$ & $\begin{array}{c}12.9 \mathrm{~dB} / 100 \mathrm{~m} \\
\mathrm{~A}=19^{*} 10^{-3} \mathrm{D}^{765}\end{array}$ \\
\hline $14.2 \mathrm{rads} / \mathrm{min} 5.1 \mathrm{Krads},-125^{\circ} \mathrm{C}$ & $\begin{array}{c}5.3 \mathrm{~dB} / 100 \mathrm{~m} \\
\mathrm{~A}=1.02 * 10^{-3} \mathrm{D}^{999}\end{array}$ & $\begin{array}{l}14.4 \mathrm{~dB} / 100 \mathrm{~m} \\
\mathrm{~A}=22^{*} 10^{-3} \mathrm{D}^{.76}\end{array}$ & $\begin{array}{c}12.3 \mathrm{~dB} / 100 \mathrm{~m} \\
\mathrm{~A}=18^{*} 10^{-3} \mathrm{D}^{765}\end{array}$ \\
\hline $.34 \mathrm{rads} / \mathrm{min}$ (Test 1) $6.5 \mathrm{Krads},-125^{\circ} \mathrm{C}$ & $5.8 \mathrm{~dB} / 100 \mathrm{~m}$ & $8.6 \mathrm{~dB} / 100 \mathrm{~m}$ & $7.0 \mathrm{~dB} / 100 \mathrm{~m}$ \\
\hline $.17 \mathrm{rads} / \mathrm{min}($ Test 2$), 6.5 \mathrm{Krads},-125^{\circ} \mathrm{C}$ & $7.9 \mathrm{~dB} / 100 \mathrm{~m}$ & $8.6 \mathrm{~dB} / 100 \mathrm{~m}$ & $7.0 \mathrm{~dB} / 100 \mathrm{~m}$ \\
\hline$>6.5 \mathrm{Krads} 25^{\circ} \mathrm{C}$, Test $2(.17 \mathrm{rads} / \mathrm{min})$ & $8.0 \mathrm{~dB} / 100 \mathrm{~m}$ & $0.15 \mathrm{~dB} / 100 \mathrm{~m}$ & $0.15 \mathrm{~dB} / 100 \mathrm{~m}$ \\
\hline $42 \mathrm{rads} / \mathrm{min}, 5.1 \mathrm{Krads},-125^{\circ} \mathrm{C}$ & $\begin{array}{c}6.1 \mathrm{~dB} / 100 \mathrm{~m} \\
\mathrm{~A}=6.5^{*} 10^{-4} \mathrm{D}^{.999} .\end{array}$ & $\begin{array}{r}15.7 \mathrm{~dB} / 100 \mathrm{~m} \\
\mathrm{~A}=23.75^{*} 10^{-3} \mathrm{D}^{.76}\end{array}$ & $\begin{array}{c}13.4 \mathrm{~dB} / 100 \mathrm{~m} \\
A=19.75^{*} 10^{-3} \mathrm{D}^{765}\end{array}$ \\
\hline $.5 \mathrm{rads} / \mathrm{min}, 6.5 \mathrm{Krads},-125^{\circ} \mathrm{C}$ & ND & $8.6 \mathrm{~dB} / 100 \mathrm{~m}$ & $7.0 \mathrm{~dB} / 100 \mathrm{~m}$ \\
\hline$>6$ Days at $-125^{\circ} \mathrm{C}, .5 \mathrm{rads} / \mathrm{min}\left(@ 25^{\circ} \mathrm{C}\right.$ ) & ND & $\sim 0.2 \mathrm{~dB} / 100 \mathrm{~m}$ & $\sim 0.2 \mathrm{~dB} / 100 \mathrm{~m}$ \\
\hline
\end{tabular}

The values in Table 6 are based on the final induced attenuation upon reaching the total dose at the specified dose rate and temperature. The equations that govern the attenuation behavior as a result of exposure are in terms of total dose, D. The objective of the testing was to determine the equations and values in rows seven, eight and nine for the ISS environmental parameters listed in column one. The equations that governed the attenuation behavior of each fiber were deduced through curve fitting techniques using the software program MATLAB. 
From Table 6 as well as previous plots, it is evident that the radiation induced attenuation for fiber $F 1$ actually increased as the fiber was tested at a lower dose rate. This is contrary to how F2 and F3 perform. In both tests for the fibers F2 and F3 as the dose rate decreased, so did the amount of radiation induced attenuation. For Fl at $28.3 \mathrm{rads} / \mathrm{min}$ to a total dose of 5.1 Krads at $-125^{\circ} \mathrm{C}$, the total attenuation at the completion of this segment of the test was $4.1 \mathrm{~dB} / 100 \mathrm{~m}$. To clarify, this implies that the dose of $5.1 \mathrm{Krads}$ at a dose rate $28.3 \mathrm{rads} / \mathrm{min}$ the signal at the output of the optical fiber was down by $4.1 \mathrm{~dB}$ for the 100 meters under test. At a lower dose rate, under the same conditions of $14.2 \mathrm{rads} / \mathrm{min}$, this attenuation increased to 5.3 $\mathrm{dB} / 100 \mathrm{~m}$. So by decreasing the dose rate by a factor of 2 , this resulted in an increase of attenuation by $1.2 \mathrm{~dB} / 100 \mathrm{~m}$ down from the previous attenuation at the higher dose rate. This result was unexpected.

The radiation induced attenuation of optical fiber F2 decreased with decreasing dose rate. At the $28.3 \mathrm{rads} / \mathrm{min}$ to a total dose of $5.1 \mathrm{Krads}$ the induced attenuation was $14.9 \mathrm{~dB} / 100 \mathrm{~m}$. By reducing the dose rate by a factor of two to $14.2 \mathrm{rads} / \mathrm{min}$ (to a TID of 5.1 Krads), the induced attenuation decreases by $.5 \mathrm{~dB} / 100 \mathrm{~m}$; from $14.9 \mathrm{~dB} / 100 \mathrm{~m}$ to $14.4 \mathrm{~dB} / 100 \mathrm{~m}$. The same is true for $\mathrm{F} 3$ where after reducing the dose rate by a factor of two the radiation induced losses decrease by $.6 \mathrm{~dB} / 100 \mathrm{~m}$. These fibers perform as expected for typical germanium doped silica. Fibers F2 and F3 perform similarly and only differ by $2 \mathrm{~dB}$ in performance under exposure. Where $F 2$ is only slightly more sensitive than $F 3$ to radiation effects.

Both fibers F2 and F3 saturate after a long exposure at the lower dose rates, however they saturate at attenuation values that differ by almost $2 \mathrm{~dB}$. The lower dose rates used in the second segment of this testing, differ by a factor of two (.34 rads/min for Test 1 and $.17 \mathrm{rads} / \mathrm{min}$ for Test 2) but have no difference in effect on fibers F2 and F3. For F2, both low dose rate data sets show that the fiber saturates at $.8 .6 \mathrm{~dB} / 100 \mathrm{~m}$ and for $\mathrm{F} 3$ the saturation point for both low dose rates is at $7.0 \mathrm{~dB} / 100 \mathrm{~m}$. In contrast, the attenuation continues to increase on fiber $\mathrm{Fl}$ showing no effects related to lowering the dose rate. It is also interesting that even when the temperature returns $1025^{\circ} \mathrm{C}$ after six days prior at $-125^{\circ} \mathrm{C}$ and it is expected that the transmission for all optical fibers would return to a nearly nonexistent attenuation, F1 continues to attenuate as if the conditions had not changed. It is possibly the case that after a few days Fl would begin to recover such that it would be evident it would eventually reach a much lower attenuation value but that was not yet evident from the 48 hours that it was monitored at room temperature. When $F 2$ and $F 3$ return to $25^{\circ} \mathrm{C}$ the losses decrease to less than $0.2 \mathrm{~dB} / 100 \mathrm{~m}$ and would probably decrease over a long period of time at this exposure. From viewing the data more closely during the last two days it does in fact appear that fibers F2 and F3 would have continued the downward trend even while being exposed to .17 rads/min.

Overall, the losses for FI for the high dose rate segment of the testing are much less than that of both F2 and F3. The loss for $\mathrm{Fl}$, after the first $5.1 \mathrm{Krads}$, is more than $10 \mathrm{~dB}$ less than the induced attenuation for F2. After the low dose rate testing, even then, F1 is still registering lower losses than F2 and F3 in the case of the higher low dose rate exposure. At the .17 rads/min dose rate exposure $\mathrm{F} 1$ is rating between the performance of $\mathrm{F} 2$ and $\mathrm{F} 3$. This in itself would be promising for the usage of this non rad hard fiber in a space environment. The only unknown is what the fiber F1 will do after constant exposure of .17 $\mathrm{rads} / \mathrm{min}$ at room temperature. Would it continue to attenuate until it reached values for radiation induced attenuation much larger than those of the high dose rate segment of F2 and F3 or would it eventually saturate and then recover to a much smaller attenuation value? Because this fiber behaves so differently than typical germanium doped optical fiber it is impossible to make any conclusions without conducting more testing. Additional testing would answer the question of whether there is a predictable pattern to the radiation induced attenuation, and whether the fiber would eventually have recovered or continued to attenuate over prolonged low dose radiation exposure.

The extrapolated data in rows seven through nine of Table 6, contains the answer to the question "how will this fiber perform in the ISS environment?". The data was extrapolated to a high dose rate of $42 \mathrm{rads} / \mathrm{min}$ with a low dose rate value of .5 $\mathrm{rads} / \mathrm{min}$ for all fibers. The largest radiation induced attenuation is seen from fiber $\mathrm{F} 2$ at $15.7 \mathrm{~dB} / 100 \mathrm{~m}$, and the lowest for $\mathrm{F} 1$ at $6.1 \mathrm{~dB} / 100 \mathrm{~m}$ assuming that the fiber $\mathrm{F} 1$ has lower losses for a greater dose rate. The data for $\mathrm{F} 1$ indicated this was so under the same $-125^{\circ} \mathrm{C}$ thermal conditions.

It is safe to assume that both F2 and F3 will perform similarly at a low dose rate of $.5 \mathrm{rads} / \mathrm{min}$ (ISS environmental requirement) to the way they performed during this testing. Therefore, a conclusion can be made based on this available data that the values for attenuation after this low dose rate exposure of $.5 \mathrm{rads} / \mathrm{min}$ are the same for both the fibers as shown in Table 6. More data would need to be available to make conclusions on how F1 would perform under the $.5 \mathrm{rads} / \mathrm{min}$ dose rate following a high dose rate exposure of $42 \mathrm{rads} / \mathrm{min}$. The only assumption that can be made based on available data is that the radiation induced attenuation would linearly increase regardless of the decrease in radiation dose rate. 


\subsection{CONCLUSIONS ON RADIATION CHARACTERIZATION}

Three types of Lucent SFT optical fiber were tested for radiation effects using two different sets of conditions towards the goal of extrapolating to the ISS radiation requirements. For both Test 1 and Test 2 the temperature remained at $-125^{\circ} \mathrm{C}$ for a total of six days and at $25^{\circ} \mathrm{C}$ for two days following. The two dose rate combinations used were chosen to make the extrapolation to a higher dose rate combination, simpler. In both tests, the first dose rate of exposure was approximately two orders of magnitude higher than the second dose rate, to match the radiation environmental requirement of the ISS specification for space flight cable. The collected data for radiation induced attenuation using two dose rate combinations of $28.3 \mathrm{rads} / \mathrm{min}$ and $.34 \mathrm{rads} / \mathrm{min}$ for Test 1 , and $14.2 \mathrm{rads} / \mathrm{min}$ and $.17 \mathrm{rads} / \mathrm{min}$ for Test 2 , was used to extrapolate to a dose rate combination of $42 \mathrm{rads} / \mathrm{min}$ and $.5 \mathrm{rads} / \mathrm{min}$. Under the conditions of $42 \mathrm{rads} / \mathrm{min}$ to a total dose of $5.1 \mathrm{Krads}$ at $-125^{\circ} \mathrm{C}$, the fiber F1 would reach an attenuation of $6.1 \mathrm{~dB} / 100 \mathrm{~m}$, F2 would reach an attenuation of $15.7 \mathrm{~dB} / 100 \mathrm{~m}$, and F3 would experience radiation induced losses of $13.4 \mathrm{~dB} / 100 \mathrm{~m}$. After a total dose exposure of $5.1 \mathrm{Krads}$ at $42 \mathrm{rads} / \mathrm{min}$, it was concluded based on available data that the induced loss for F1 could not be predicted but the losses for F2 and F3 would be $8.6 \mathrm{~dB} / 100 \mathrm{~m}$, and $7.0 \mathrm{~dB} / 100 \mathrm{~m}$ respectively. After completion of the six days at $-125^{\circ} \mathrm{C}$, it is expected that both $\mathrm{F} 2$ and $\mathrm{F} 3$ would return to less than $0.2 \mathrm{~dB} / 100 \mathrm{~m}$ during low dose rate exposure of $.5 \mathrm{rads} / \mathrm{min}$ over a prolonged exposure. The ISS requirement states that the total dose should be $50.4 \mathrm{Krads}$ at the lower dose exposure and requires a low dose rate of .24 $\mathrm{rads} / \mathrm{min}$. It is expected that even up to a total dose of $50.4 \mathrm{Krads}$ that the losses for F2 and F3 would still be less than -0.2 $\mathrm{dB} / 100 \mathrm{~m}$. The low dose extrapolation was performed for a dose rate of $.5 \mathrm{rads} / \mathrm{min}$ but by available data the results show that the effects are the same regardless of a factor of 2 decrease in dose rate. This conclusion was made based on the low dose rate data for both $\mathrm{F} 2$ and $\mathrm{F} 3$. It was not apparent that a recovery would occur for $\mathrm{F} 1$ and for now it can only be assumed that the radiation induced attenuation for $\mathrm{F} 1$ would only continue to increase even at a low dose rate of $.5 \mathrm{rads} / \mathrm{min}$ while at $25^{\circ} \mathrm{C}$.

\section{RESULTS OF OUTGASS TESTING}

The FLEX-LITEß $1.2 \mathrm{~mm}$ type optical fiber cable manufactured by W.L. Gore can contain optical fiber with an acrylate coating. This configuration can be ordered with a variety of optical fibers inside. The FON8383 part number is specific to the selection of an acrylate coated fiber rated for $980 \mathrm{~nm}$ and the part number FON1008 is a multimode version with a $62.5 / 125$ optical fiber inside. This cable configuration with an acrylate coated fiber was tested in configuration by the Materials Engineering Branch at NASA Goddard Space Flight Center. Two 1.5 meter samples of the cable with fiber inside were tested at $80^{\circ} \mathrm{C}$ and at $125^{\circ} \mathrm{C}$ in a vacuum environment of $10^{-6}$ Torr for 24 hours. The cables were open on both ends, unterminated. The results state that the amount of \%TML was $.24 \%$ and $.34 \%$ respectively. Both results show that acrylate coated fiber can in fact, be used inside of a "non outgassing" cable configuration such as the $1.2 \mathrm{~mm}$ FLEX-LITE® series configuration made by W.L. Gore. It was also verified by other data that the \%TML did not change with a change in length of the cable. This cable with acrylate fiber inside passes the requirement of the ASTM-595 outgassing test in a configuration.

\section{CONCLUSIONS}

Examined here were several optical fiber cables and optical fiber for their suitability in typical space flight environments. The W.L.Gore FON 1008 cable was tested with acrylate fiber inside for its suitability in a thermal vacuum environment. The W.L.Gore FON1004, the Brand Rex OCI614 and OC1008 and the Northern Lights H06 and HL1 made for RIFOCS were examined for thermal stability for the parameters of length shrinkage and optical stability. Lastly three 100/140/172 polyimide, carbon coated optical fibers made by Lucent SFT were tested for their suitability of use in the ISS space radiation environment at $-125^{\circ} \mathrm{C}$

\section{REFERENCES}

I. Melanie N. Ott, Jeannette Plante, Jack Shaw, M. Ann Garrison-Darrin, "Fiber Optic Cable Assemblies for Space Flight Applications: Issues and Remedies," Paper 975592 SAE/AIAA 1997 World Aviation Congress, October 13-16, Anaheim, CA.

2. Melanie N. Ott, "Fiber Optic Cable Assemblies for Space Flight II: Thermal and Radiation Effects," Photonics For Space Environments VI, Proceedings of SPIE Vol. 3440, 1998.

3. Melanie N. Ott, Joy Bretthauer, "Twelve Channel Optical Fiber Connector Assembly: from Commercial off the Shelf to Space Flight Use," Photonics For Space Environments VI, Proceedings of SPIE Vol. 3440, 1998, pp 57-68. 
4. Melanie N. Ott, "Electron Induced Scintillation Testing of Commercially Available Optical Fibers for Space Flight," 1999 IEEE Radiation Effects Data Workshop, IEEE Nuclear and Space Radiation Effects Conference, July 1999.

5. Outgassing Data for Selecting Spacecraft Materials Online, URLis http://epims.gsfc.nasa.gov/og/

6. ISS Fiber Optic Failure Investigation Root Cause Report, August I, 2000 WWW URL: http://issfoc.gsfc.nasa.gov/iss/team2/finalreport/Root_Cause.pdf

7. International Space Station Specification SSQ 21657, WWW URL, http://misspiggy/tva/issfo/spec/issnewspec.html

8. H. Henschel, O. Kohn, H.U. Schmidt, "Radiation Induced Loss Measurements of Optical Fibres with Optical Time Domain Reflectometers (OTDR) at High and Low Dose Rates,", IEEE 1992.

9. E. J. Friebele, M.E. Gingerich, D. L. Griscom, "Extrapolating Radiation-Induced Loss Measurements in Optical Fibers from the Laboratory to Real World Environments", $4^{\text {th }}$ Biennial Department of Defense Fiber Optics and Photonics Conference, March 22-24, 1994.

\section{Acknowledgements}

Most endeavors of this magnitude are accomplished by a team effort if they are to be successful. We would like the acknowledge the following people of our team who make this endeavor a success:

Claude Smith, QSS/ NASA GSFC

John Slonaker, QSS/ NASA GSFC

Steve Brown, NASA GSFC

Harry Shaw, NASA GSFC

Michelle Manuel, NASA GSFC

Shawn Macmurphy, Sigma Research and Engineering/ NASA GSFC

Jesse Frank, Swales Aerospace/ NASA GSFC

Matt Bettencourt, Sigma Research and Engineering / NASA GSFC

Faruq Sabur, NASA GSFC

Jeff Frazier, Swales Aerospace / NASA GSFC

Ken LaBel, NASA GSFC

Doug Hardy, W.L.Gore

Joe Gallo, W.L. Gore

Dennis Horwitz, RIFOCS

Dr. Jie Li, Lucent SFT 